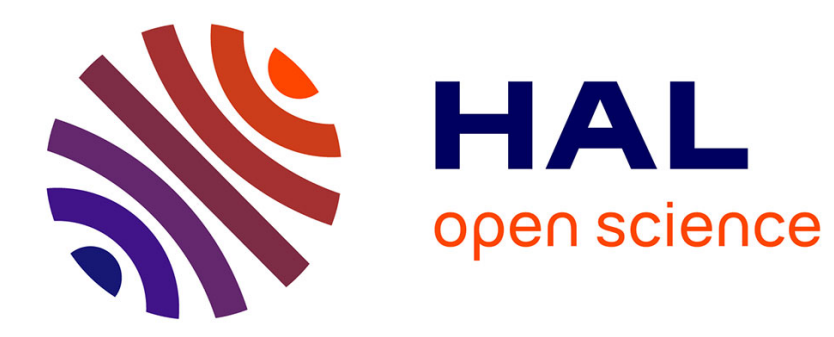

\title{
Scanning tunneling microscopy
}

J. Gimzewski

\section{To cite this version:}

J. Gimzewski. Scanning tunneling microscopy. Journal de Physique IV Proceedings, 1993, 03 (C7), pp.C7-41-C7-48. 10.1051/jp4:1993704 . jpa-00251710

\section{HAL Id: jpa-00251710 https://hal.science/jpa-00251710}

Submitted on 1 Jan 1993

HAL is a multi-disciplinary open access archive for the deposit and dissemination of scientific research documents, whether they are published or not. The documents may come from teaching and research institutions in France or abroad, or from public or private research centers.
L'archive ouverte pluridisciplinaire HAL, est destinée au dépôt et à la diffusion de documents scientifiques de niveau recherche, publiés ou non, émanant des établissements d'enseignement et de recherche français ou étrangers, des laboratoires publics ou privés. 


\title{
Scanning tunneling microscopy
}

\author{
J.K. GIMZEWSKI
}

IBM Research Division, Zurich Research Laboratory, Säumerstr. 4, 8803 Rüschlikon, Switzerland

\begin{abstract}
A brief review of the state-of-the-art of scanning tunneling microscopy (STM) is presented with emphasis on materials problems. I shall discuss in particular the variety of materials, environments and temperatures that can be investigated. In addition to topographic studies, some examples of STM as local probe are given. It is proposed that STM be increasingly incorporated as a technique for investigation of real materials problems.
\end{abstract}

\section{Introduction}

Scanning tunneling microscopy (STM) was the first of a family of scanned probe microscopies [1] whose development commenced some eleven years ago by Binnig, Rohrer and coworkers [2]. Originally, it was conceived as a microscopy to investigate thin oxide films for the Josephson device technology. But the method went far beyond original expectations and remains to date the ultimate atomic resolution probe for investigating surface structures and the local physical properties of electrically conductive materials (even those with thin insulating overlayers). In this paper, which is a summary of my Plenary lecture at Euromat 1993, I shall convey the state-of-the-art with particular emphasis on materials problems and technology.

Commercial STM systems are now available from a variety of vendors, which has increased the general availability of the technique to researchers in a diverse range of disciplines. We are also seeing a general trend towards using the technique to investigate specific materials-related problems as a consequence of growing instrumental sophistication and ease of use. Technological problems increasingly involve issues on the nanometer or atomic scale and STM provides a unique real-space insight into the world of these dimensions. During the early stages of development of STM, researchers tried to image a whole variety of surfaces, but the results obtained were often disappointing. Many systems that readily delivered atomic resolution, such as graphite, related CDW compounds, $\mathrm{Si}(111)-(7 \times 7)$ and other reconstructed semiconductor surfaces as well as reconstructed single-crystal metal surfaces, became the subject of intense interest. Today, we see a return to the study of more complex and, from a materials outlook, relevant systems taking advantage of the instrumental advances and theoretical and experimental understanding acquired over the past decade.

What impact might STM have on your own surface-related research programs? The theme of this paper is to reevaluate STM's impact and future utility in technology and science. I have selected a number of examples that give a flavor of the capability and diversity of what STM can contribute to the inspection and analysis of materials in various 
environments. If we consider the requirements of a surface-specific microscopy that could cope with a diverse range of problems, then the following list of wishes would spring to the mind of many working in the field:

a) Inspection in gaseous and liquid environments at temperatures similar to the actual operating conditions of the surface.

b) High spatial resolution as well as a large scan range.

c) Reasonable data acquisition rates.

d) Methods and theories for data interpretation.

e) Additional local spectroscopies and probes of physical phenomena relevant to the problem considered.

STM has all of the above capabilities.

\section{Environment: Electrochemistry}

I shall first discuss the environment in which the STM can operate. Liquids are one of the most common environments in biology, while in air the majority of surfaces are covered
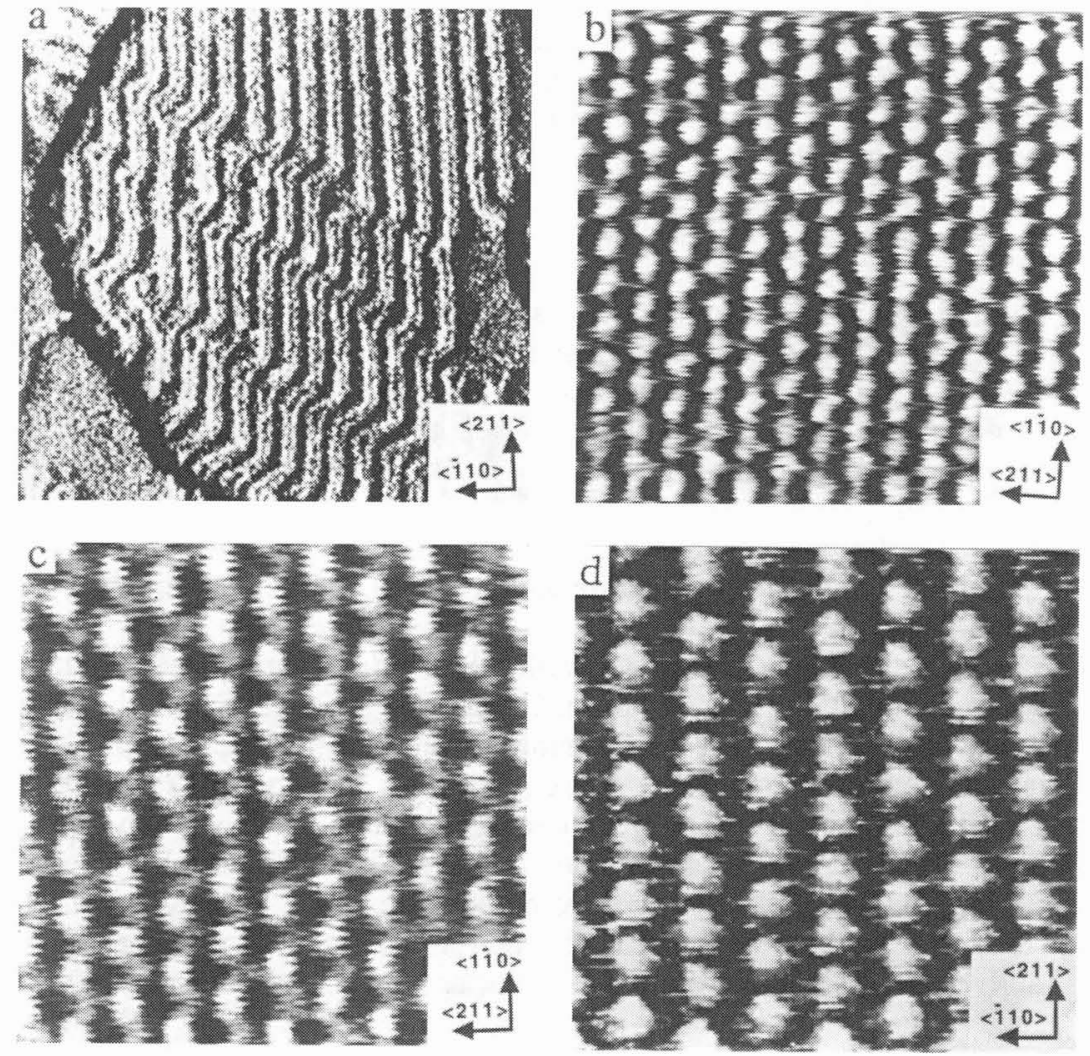

Figure 1 STM images of a gold-copper system in an electrochemical environment. (a) Large-scale image showing reconstructed $\mathrm{Au}(111)$ in $0.1 \mathrm{mM} \mathrm{H}_{2} \mathrm{SO}_{4}+1 \mathrm{mM} \mathrm{CuSO}_{4}$ at $E=+300 \mathrm{mV}$ vs. $\mathrm{Cu} / \mathrm{Cu}^{2+}\left(1300 \times 1300 \AA^{2}\right)$. (b) At more positive potential, reconstruction is lifted leaving as $(1 \times 1)$ gold structure $\left(E=+600 \mathrm{mV} ; 35 \times 35 \AA^{2}\right)$. (c) Same surface in $50 \mathrm{mM} \mathrm{Na}_{2} \mathrm{SO}_{4}+5 \mathrm{mMCuSO}_{4}$ at $E=+20 \mathrm{mV}$ showing a $p(2 \times 2)$ overlayer. (d) $(\sqrt{3} \times \sqrt{3}) \mathrm{R} 30^{\circ}$ structure under same conditions as in (c), but at $V_{\mathrm{t}}=+180 \mathrm{mV}$. (Courtesy of J.K. Sass, see Ref. 3). 
by a water layer, and oil-lubricated surfaces are prevalent in an engineering environment. Electrochemical processes, which are the most complex of all, take place in a corrosive environment of ions and solvent molecules where a variety of reactions can be induced by selecting the potential drop across the metal/solution interface. The introduction of STM into specially designed electrochemical cells to study processes in situ is a excellent example of STM's powerful contributions to our understanding of surface modifications previously inaccessible to the researcher in real space. Fig. 1 shows an example of a Au(111) surface imaged at atomic resolution in an electrochemical cell containing sulfuric acid and $\mathrm{CuSO}_{4}$. Depending on the electrochemical parameters one can switch the surface from (a) a reconstructed $\mathrm{Au}(111)$ state to (b) an unreconstructed state to a $\mathrm{Cu}-p(2 \times 2)$ overlayer or to a $\sqrt{3} \times \sqrt{3} \mathbf{R}^{\circ} 0^{\circ}$ overlayer [3]. The STM results show directly the influence of the electrochemical parameters on the atomic surface structure and can be simultaneously compared with cyclic voltammograms. The latter is the usual method used by electrochemists to investigate the influence of the electrode potential.

\section{Nanophase materials: Porous silicon}

"Nanophase" refers to materials with particle dimensions on the nanoscale [4]. This class of materials as well as nanocomposites often have properties significantly different from the bulk crystalline material. Electrochemical anodization of silicon causes the formation of a sponge-like structure (porous silicon (PS)) which emits light efficiently in the visible range $[5,6]$. Calculations by Buda et al. [7] have modelled PS by silicon wire structures with diameters that exhibit a direct optical gap at $k=0$ and shift the gap energy into the visible range. Figure 2 shows a high-resolution STM topograph of $85 \%$ PS. Great care is required to image PS due to its delicate structure. This and other images show protrusions of $\approx 1 \mathrm{~nm}$ in height with lateral dimensions of 1-5 nm which is in the range of lateral dimensions expected for the proposed quantum-sized effects [8]. In addition, light measured simultaneously from PS using STM as a local electron excitation source [9] has shown that the light emission varies on a similar scale [8]. This example illustrates the use of STM as a local probe for luminescence on a scale relevant to its structural origins. STM has also been successfully applied to semiconductor interfaces and quantum well structures such as those used for GaAs/AlGaAs laser diodes. STM and tunneling spectroscopy [10], in conjunction with scanning electron microscopy used to position the tip above the structure, have been able to locate and probe the electronic structure of the GaAlAs layers. More recently, atomicscale composition fluctuations in similar structures have also been observed [11]. Local light emission from quantum well structures using STM as a local cathodoluminescent source is an additional characterization technique for these materials [12].

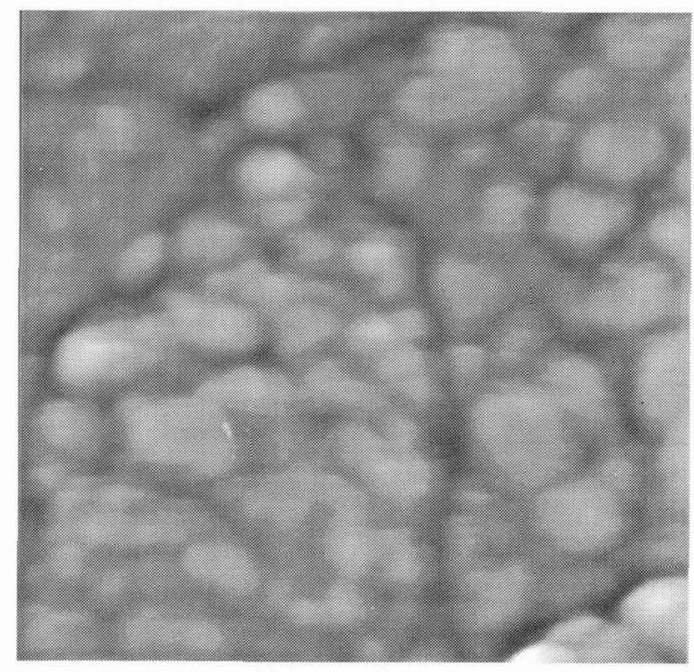

Figure 2 High-resolution STM topograph of a $25 \times 25 \mathrm{~nm}$ area of $85 \%$ PS rendered as a $3 \mathrm{D}$ pseudo-illuminated image. Image recorded with $V_{\mathrm{t}}=-5 \mathrm{~V}$ at a constant set current of $1 \mathrm{nA}$. (See Ref. 8). 


\section{Oxide formation and oxides}

Titanium, its oxides and alloys are materials of considerable interest for technologies such as medical implants and the aerospace industry. Biocompatibility, corrosion resistance and catalytic behavior are some of the key issues that spring to mind when considering their surface properties. Figure 3 shows a topograph of a series of the initial stages of oxidation of the clean surface. The image consists of flat (0001) terraces and steps [13]. The initial stages of reaction with the surface result in the formation of oxide islands at the steps, which are chemically more reactive, and nanoscopic islands of oxide nuclei. These are observed as small bump-like protrusions in the image. These oxide nuclei show a very interesting dependence on the imaging voltage shown in Fig. 4, which shows that the protrusions change into depressions depending on tip polarity [14]. This bias dependence can be interpreted in terms of a modification of the local density of states depending on whether one tunnels through occupied or unoccupied states. It also provides additional chemical information on the oxide clusters.

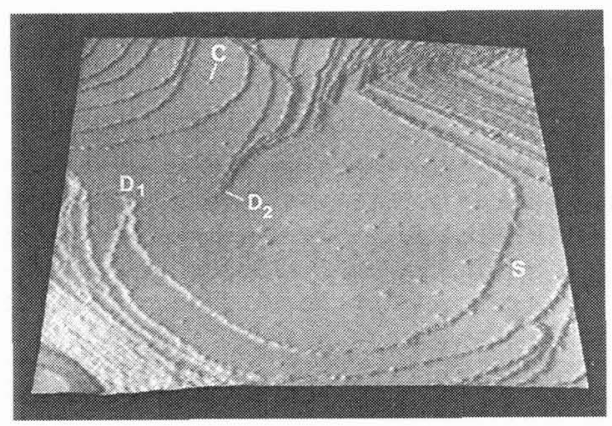

Figure 3 STM topograph of a $2000 \AA \times 2000 \AA$ area of a Ti film displayed as a pseudo-illuminated image. The data was acquired at $I_{\mathrm{t}}=1 \mathrm{nA}$ and $V_{\mathrm{t}}=-3.7 \mathrm{~V}$. The vertical extension is $60 \AA . D_{1}$ and $D_{2}$ are dislocations; $S$ are steps and $C$ are oxide nuclei. From [13].

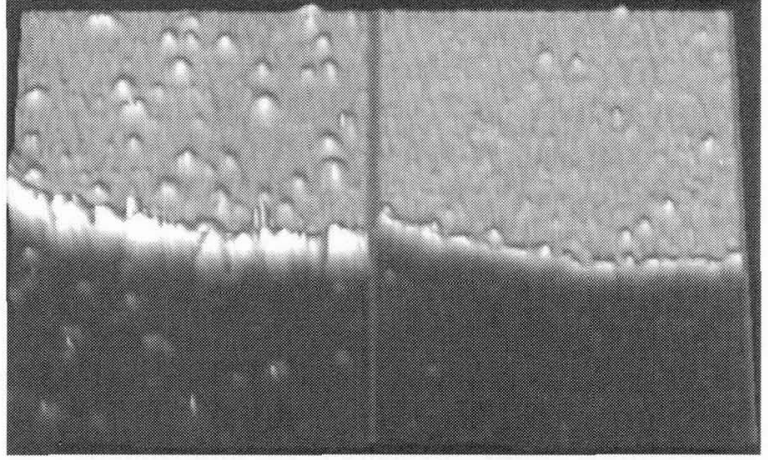

Figure 4 Bias dependence of STM topographs of an $200 \times 300 \AA$ area of a Ti film that has been exposed to $20 \mathrm{~L}$ of molecular oxygen. Topographs rendered as pseudo-3D images are shown for $I_{\mathrm{t}}=1 \mathrm{nA}$ and $V_{\mathrm{t}}=3.5 \mathrm{~V}$ (right) and $-3.6 \mathrm{~V}$ (left). A monoatomic step is seen running through the image.

Local photon emission mapping of the oxidized surface also provides additional information on the chemical composition of the surface. Figure 5 shows (a) a topography and (b) a photon map of partially oxidized Ti. The bright areas in (b) indicate a local metallic character and result from light emitted from specific plasmon modes that are excited by the tunneling electrons $[13,14]$. Going beyond the initial stages of oxidation of $\mathrm{Ti}$, it is also possible to image bulk $\mathrm{TiO}_{2}$ itself. Figure 6 shows a $\mathrm{TiO}_{2}(100)$ surface. Upon heating, it forms a $1 \times 3$ reconstruction resulting in one-dimensional rows $\approx 14 \AA$ apart which, using tunneling spectroscopy, have been shown to contain oxygen vacancies on top of the rows [15]. The observation of oxygen vacancies are important for technological applications of oxides in ceramic fracture, catalysis and photovoltaic devices. The ability of STM to probe individual vacancies electronically offers a new perspective in oxide research and allows investigations of their chemical reactivity to be studied in situ. 

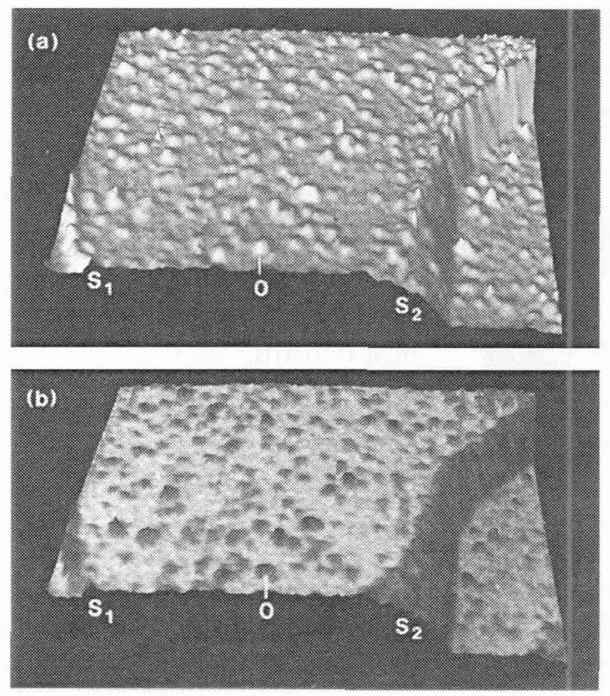

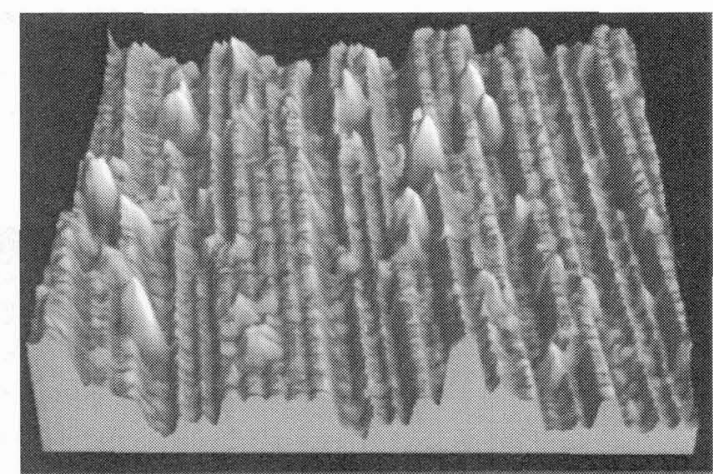

Figure $6 \mathrm{STM}$ image of $\mathrm{TiO}_{2}(100)(1 \times 3)$. Atomic rows run along [001] direction. The rows have a periodicity of $13.771 \AA$ and a corrugation amplitude of $\approx 2 \AA$.

Figure 5 (a) STM topograph of a $1000 \AA \times 1000 \AA$ area of a Ti film that has been exposed to $20 \mathrm{~L}$ of $\mathrm{O}_{2}$ at room temperature, rendered as a pseudo-illuminated image. The vertical extension is $20 \AA$. The STM was operated in constant-constant mode with $I_{\mathrm{t}}=50 \mathrm{nA}$ and $V_{t}=-3.7 \mathrm{~V}$. (b) Integral photon intensity (photon map) recorded simultaneously with the topography shown in (a). The intensity values are represented by a gray-scale used to shade the topographic image. The intensity scale ranges linearly from 0 to $1000 \mathrm{cps}$ (counts per second). From [13].

\section{Superconductivity oxides}

Another class of oxides of current interest are cuprate semiconductors in which the microstructure of thin films and bulk material plays an important role. In particular STM has revealed a high density of screw dislocations which are potential vortex pinning sites for low magnetic fields and which directly affect film growth [16]. The routine use of STM by Gerber et al. [17] to examine $\mathrm{YBa}_{2} \mathrm{Cu}_{3} \mathrm{O}_{7-\delta}$ films with different growth parameters has enabled conditions to be optimized for sputter deposition. Figure 7 shows an example of a growth spiral emanating from both left and right-hand screw dislocations for this material deposited on $\mathrm{SrTiO}_{3}(100)$. This particular example shows how STM can be applied directly and usefully to a complex materials problem.

\section{Molecular imaging: Fullerenes}

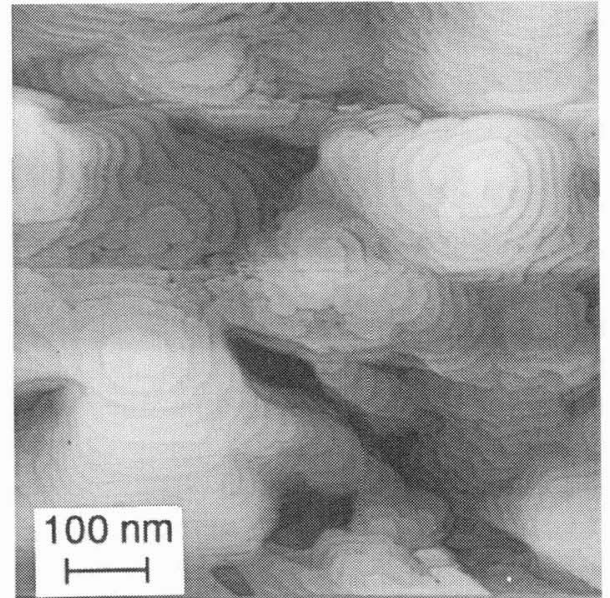

Figure 7 STM image of a sputtered $\mathrm{YBa}_{2} \mathrm{Cu}_{3} \mathrm{O}_{7-\delta}$ film grown on $\mathrm{SrTiO}_{3}$ (100) showing growth spirals emanating from both left and right-hand screw dislocations. From [16].

STM has permitted the first observations of individual molecules in a range of environments. Biopolymers and biological membranes can also be studied on the nanometer scale. Refs. [18] review the range of organic and biological materials that can be studied with atomic force microscopy and/or STM. The advantages of STM concern not only resolution 
and environment, they include the low-energy (meV-eV) of the tunneling electrons used to probe delicate samples. The following classes of molecular systems have been investigated: physisorbed molecules such as alkanes, organic conductors, as well as macromolecules such as DNA and bacteria.

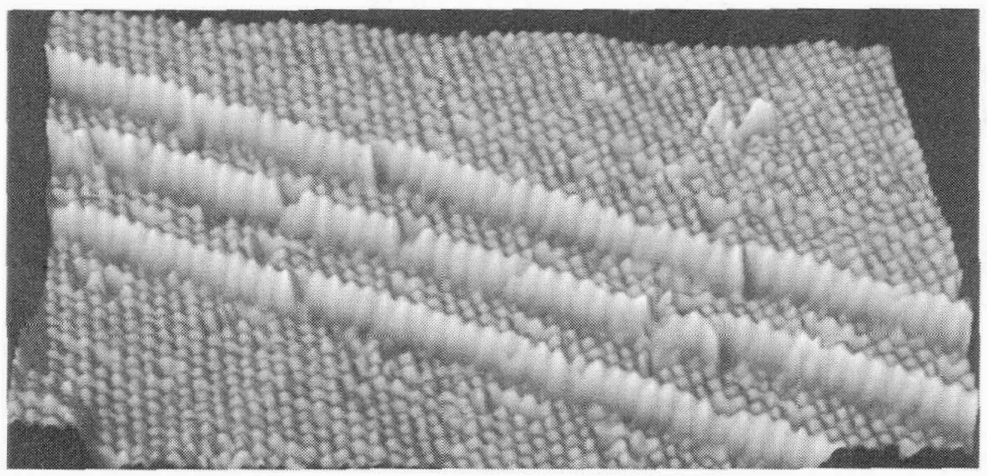

Figure 8 (left) Full monolayer of $\mathrm{C}_{60}$ on $\mathrm{Au}(111)$ showing $\mathrm{Au}$ monoatomic steps.

Figure 9 (below) Internal molecular structure in $\mathrm{C}_{60}$ imaged by STM. This molecular class was found using multivariate statistical analysis (MSA) as described in the text.

An intense interest in fullerenes [19] has also developed recently. STM studies have been conducted on $\mathrm{C}_{60}$ molecules to determine their positions on the various substrates, i.e. primarily noble metal surfaces, but also GaAs and silicon surfaces [20]. With a nominal diameter of the $C_{60}$ sphere of $7 \AA$ it is clear that STM can resolve intramolecular structure [21]. Figure 8 shows a well-ordered hexagonal monolayer array of $\mathrm{C}_{60}$ deposited on $\mathrm{Au}(111)$ after annealing. One observes also two gold monoatomic steps from the underlying substrate. STM appears to be ideally suited to study and optimize the growth conditions for welldefined fullerene thin films. Additionally the internal structure of the molecule can be observed as illus-

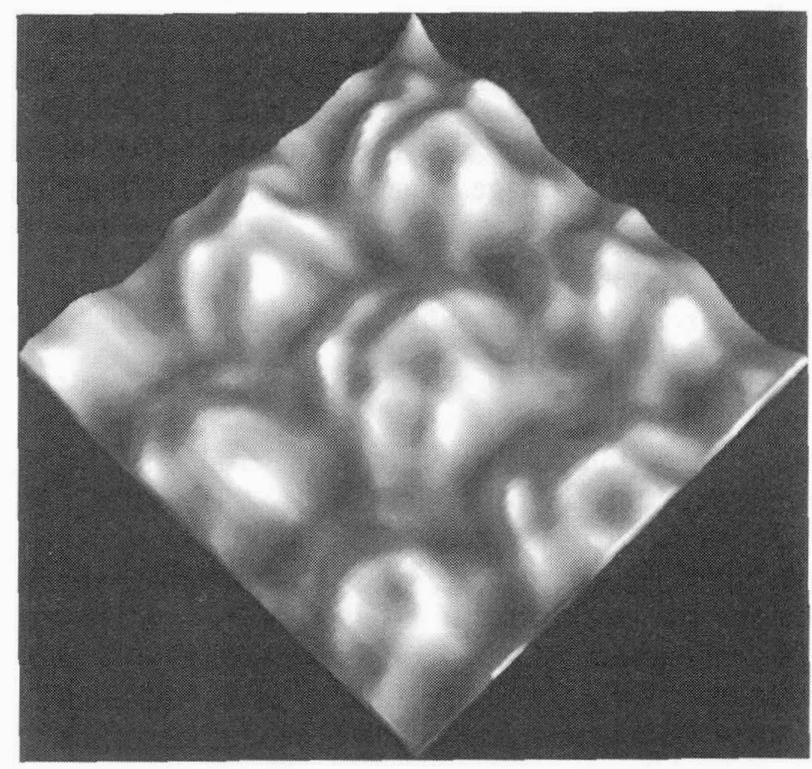
trated in Fig. 9, which shows a single $\mathrm{C}_{60}$ molecule surrounded by six neighbors exhibiting a complex internal structure. This image was produced from a series of images using multivariate statistical analysis (MSA) [22], which enables classes of molecules to be identified and clustered. MSA procedures used in transmission electron microscopy are foreseen to be employed increasingly given the large amount of data that one can collect with STM. Another related development is dynamical studies. Through time-lapse imaging, video sequences of chemical reactions, diffusion and motion of domains can be readily analyzed [23]. This latter development owes its success to faster and better instrumentation, as well as to computer control. 


\section{Temperatures}

The temperature range where STM can operate covers cyrogenic temperatures up to about $1100{ }^{\circ} \mathrm{C}$. Low-temperature together with ultrahigh vacuum represent an ideal research environment similar perhaps only to that found naturally somewhere in outer space where atomic and molecular mobility is frozen, where the electrical noise in the tunnel junction is minimal and where the stability and drift rates of the STM tip across the surface amount to less than 1 atomic diameter/hour. Stabilities achieved by Eigler and coworkers [24] are in the range of one-thousandth of an atomic diameter. This has enabled subtle new physics to be visualized and atoms to be actually pushed, pulled and positioned on an individual basis [24]. Even a small drop in temperature can assist in imaging mobile surfaces such as the $\mathrm{Si}(100)$ surface in which dimers of $\mathrm{Si}$ atoms, which normally oscillate between two bonding states at room temperatures, are frozen in [25]. For molecules such as the fullerene $C_{60}$, which is highly mobile at room temperature, all rotational motion can be frozen out and its internal molecular structure examined [26, 27]. Moving on to high temperatures, many interface formation, oxidation and catalytic processes occur at elevated temperatures. Carefully designed STM systems can operate at these high temperatures. Feenstra et al. have imaged a Ge(111) surface at $280{ }^{\circ} \mathrm{C}$ and observed a disordered region of the otherwise ordered Ge lattice as the surface undergoes a reversible phase transition from a $c 2 \times 8$ structure into a $1 \times 1$ state as the temperature is slowly increased [28]. More recently, Wong et al. [29] have achieved images of silicide formation at temperatures up to $1100^{\circ} \mathrm{C}$.

\section{Concluding remarks}

I have selected a few examples to give some flavor of the current status of STM for the investigation of a broad range of materials and systems in various different environments. STM is quite a mature technique and is capable of providing useful information on materials characterization. In this review I have omitted more recent developments in new local probe techniques that enable chemical reactions as well as electronic, magnetic, and other properties of atomic or nanometer-sized areas to be investigated [1]. The development of these probes to the same level as topographic imaging and their incorporation into commercial instrumentation should in future provide scientists and technologists working in the field of materials research with further chemical probing capabilities.

Acknowledgment. I would like to thank Ch. Gerber, B. Reihl, J.K. Sass, M. van Heel, J. Rabe, M. Welland and R. Berndt for useful discussions. I also thank H. Rohrer for his support and $\mathrm{L}$. Pavka for preparing this manuscript at short notice.

\section{References}

[1] ROHRER H., in Highlights in Condensed Matter Physics and Future Prospects, NATO ASI Series B, Vol. 285, edited by L. Esaki (Plenum Press, New York and London, 1991) p. 465.

[2] BINNIG G. and ROHRER, H., Helv. Phys. Acta 55 (1982) 726.

[3] HAISS W., SASS J.K., LACKEY D. and VAN HEEL M., Proc. AFM/STM Symp. Natick, MA, June 8-10, 1993; see also HAISS W., LACKEY D., SASS J.K., MEYER H. and NICHOLS R.J., Chem. Phys. Lett. 200 (1993) 343.

[4] Nanophase and Nanocomposite Materials, edited by S. Komarneni, J.C. Parker and G.J. Thomas, MRS Symp. Proc. Series, Vol. 186 (1993).

[5] CANHAM L.T., Appl. Phys. Lett. 57 (1990) 1046.

[6] CULLIS A.G., CANHAM L.T., Nature 353 (1991) 335.

[7] BUDA F., KOHANOFF J. and PARRINELLO M., Phys. Rev. Lett. 69 (1992) 1272.

[8] DUMAS Ph. GU M., SYRYKH C., GIMZEWSKI J.K., MAKARENKO I., HALLIMAOUI A., SALVAN F., Europhys. Lett. (1993) in press.

[9] BERNDT R. and GIMZEWSKI J.K., Phys, Rev, B 45 (1992) 14095. 
[10] ALBREKTSEN O. and SALEMINK H., J. Vac. Sci. Technol. B 9 (1991) 779; ALBREKTSEN O., ARENT D.J., MEIER H.P., SALEMINK H.W.M., Appl. Phys. Lett. 57 (1990) 31.

[11] SALEMINK H.W.M. and ALBREKTSEN O., Phys. Rev. B 47 (1993) in press.

[12] ABRAHAM D.L., VEIDER A., SCHÖNENBERGER Ch., MEIER H.P., ARENT D.J. and ALVARADO S.F., Appl. Phys. Lett. 56 (1990) 1564; RENAUD Ph., and ALVARADO S.F., Phys. Rev. B 44 (1991) 6340.

[13] BERNDT R., GIMZEWSKI J.K. and SCHLITTLER R.R., Ultramicroscopy $42-44$ (1992) 355.

[14] GIMZEWSKI J.K., BERNDT R. and SCHLITTLER R.R., in Nanosources and Manipulation of Atoms under High Fields and Temperatures: Applications, NATO ASI Series E, Vol. 235, edited by V.T. Binh et al. (Kluwer Academic Publishers, Dordrecht, 1993) p. 219.

[15] MURRAY P.W., LEIBSLE F.M., FISHER H.J., FLIPSE C.F.J., MURYN C.A. and THORNTON G., Phys. Rev. B 46 (1992) 12877.

[16] SCHLOM D.G., ANSELMETTI D., BEDNORZ J.G., BROOM R.F., CATANA A., FREY T., GERBER Ch., GÜNTHERODT, H.-J., LANG H.P. and MANNHART J., Z. Phys. B Condensed Matter 86 (1992) 163.

[17] GERBER Ch., ANSELMETTI D., BEDNORZ J.G., MANNHART J. and SCHLOM D.G., Nature 350 (1991) 279.

[18] For a review see RABE J.P., Ultramicroscopy 42-44 (1992) 41; GIMZEWSKI J.K. in Electron Crystallography of Organic Materials edited by J.R. Fryer and D.L. Dorset (Kluwer, Dordrecht, 1990) p. 203; $42-44$ (1992) 41; FROMMER, J., Angew. Chem., Int. Ed. Eng. 31 (1992) 1298.

[19] For a review see PRASSIDES K. and KROTO, H., Physics World 5 (1992) 44.

[20] WILSON R.J. et al. Nature, 348 (1990) 621; WRAGG J.L., CHAMBERLAIN J.E., WHITE H.W., KRÄTSCHMER W., HUFFMAN D.R., Nature, 348 (1990) 623; LI Y.Z., CHANDER M., PATRIN J.C., WEAVER J.H., CHIBANTE L.P.F., SMALLEY R.E., Science, 252 (1991) 547; ZHANG Y., GOA X., WEAVER M.J., J. Phys. Chem., 96 (1992) 510; LAMB L.D. et al,, Science, 255 (1992) 1413; CHEN T et al., Phys. Rev. B, 45 (1992) 14411.

[21] ALTMAN E.I. and COLTON R.J. Surf. Science, 274 (1992) 49; HOWELLS S. et al. Surf. Science, 274 (1992) 141; CHEN T. et al., J. Vac. Sci. Technol. B, 9 (1991) 2461; LANG H.P. et al., Europhys. Lett., 18 (1992) 29; Appl. Phys. A, 56 (1993) 197; HASHIZUME T. et al., Jpn. J. Appl. Phys., 31 (1992) L880.

[22] See VAN HEEL M., Optik 82 (1989) 114. IMAGIC-5 was used to process the data. This software has been developed by Dr. M. van Heel and coworkers.

[23] Video images are a regular part of STM conferences. See for example Proc. 6th Int'l Conf. on STM, Interlaken, Switzerland, 12-16 Aug. 1991, Ed. P. Descouts and H. Siegenthaler, Ultramicroscopy, 42-44 (1992).

[24] EIGLER D.M. and SCHWEIZER E.K., Nature 344 (1990) 524.

[25] WOLKOW R., Phys. Rev. Lett., 68 (1992) 2636.

[26] GAISCH R., BERNDT R., GIMZEWSKI J.K,, REIHL B., SCHLITTLER R.R., SCHNEIDER W.D. and TSCHUDY M., Appl. Phys. (in press); Nature (submitted).

[27] For a description of LT-UHV-STM instrumentation see: GAISCH R., GIMZEWSKI J.K., REIHL B., SCHLITTLER R.R., TSCHUDY M. and SCHNEIDER W.D., Ultramicroscopy 42-44 (1992) 1621.

[28] FEENSTRA R.M., SLAVIN A.J., HELD G.A. and LUTZ M.A., Phys. Rev. Lett. 66 (1991) 3257.

[29] WONG T. and WELLAND M. (private communication). 